\title{
Myocardial oxygenation is reduced in end-stage renal failure: a novel blood oxygen level dependant (BOLD)-cardiac MRI study
}

\author{
Susie F Parnham ${ }^{1,3}$, Suchi Grover ${ }^{1,3}$, Craig Bradbrook ${ }^{3 *}$, Darryl Leong ${ }^{1}$, Carmine De Pasquale ${ }^{1}$, Jonathan Gleadle ${ }^{2}$, \\ Joseph Selvanayagam ${ }^{1,3}$
}

From 17th Annual SCMR Scientific Sessions

New Orleans, LA, USA. 16-19 January 2014

\section{Background}

Cardiovascular disease is the leading cause of mortality and morbidity in end-stage renal failure (ESRF) population, mostly from coronary artery disease (CAD). Majority of CAD in ESRF patients is asymptomatic and current cardiac stress imaging modalities are sub-optimal as risk predictors. Advances in cardiovascular magnetic resonance (CMR) with the novel blood oxygen level-dependent (BOLD) technique provides unprecedented capability to assess regional myocardial deoxygenation. We hypothesized that myocardial oxygenation would be reduced in ESRF patients and may form a novel strategy to assess myocardial ischemia.

\section{Methods}

Sixteen chronic renal failure (CRF) patients (7 on dialysis, 9 pre-dialysis) with no known history of CAD underwent CMR scanning at 3.0 T. Given known reductions in BOLD signals in hypertrophied myocardium, we also assessed a control group of HT patients with no history of CAD $(n=6)$ Myocardial function, rest and stress BOLD was performed. To measure oxygenation, using a T2-prepared BOLD sequence, myocardial Signal Intensity (SI) was measured at adenosine stress $(140 \mu \mathrm{g} /$ $\mathrm{kg} / \mathrm{min}$ ) and at rest (corrected to RR interval). Comparison of myocardial SI analyses were performed using multivariate linear regression.

\section{Results}

Baseline clinical characteristics were similar in both CRF case and HT control groups, except higher body mass index in HT group $(\mathrm{p}=0.02)$. Left and right ventricular dimensions and functions were similar. Interventricular septal thickness and LV mass were similar in both RF case and HT control groups (LV septum: $1.2 \pm 0.1 \mathrm{~cm}$ RF vs $1.2 \pm 0.1 \mathrm{~cm} \mathrm{HT}, \mathrm{p}>\mathrm{NS}$; LV mass index $78 \pm$ $6 \mathrm{~g} / \mathrm{m} 2 \mathrm{RF}$ vs $63 \pm 4 \mathrm{~g} / \mathrm{m} 2 \mathrm{HT}$, p > NS). Rate Pressure Product (RPP) was similar in both groups. Global myocardial BOLD SI change was significantly lower in RF case group compared to HT control group $(-1.79 \pm 9.13$ vs $17.36 \pm 9.19, \mathrm{p}=0.0004$ ) (Figure 1$)$. BOLD SI Change globally and in the LAD and RCA coronary artery territory level were significantly lower in patients with renal failure (Table 1), (although did not reach statisticalsignificance in the left circumflex territory).

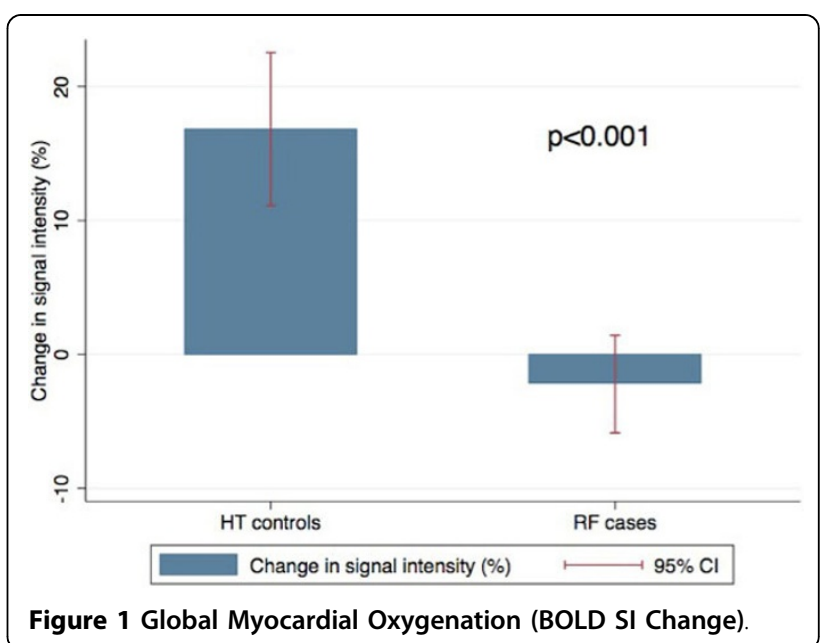

${ }^{3}$ Cardiovascular Magnetic Resonance Research, Flinders Medical Centre, Bedford Park, South Australia, Australia

Full list of author information is available at the end of the article 
Table 1 Myocardial Oxygenation in Left Anterior Descending (LAD), Left Circumflex (LCx) and Right Coronary Artery (RCA) Territories

\begin{tabular}{cccc}
\hline BOLD SI Change & $\begin{array}{c}\text { RF Cases } \\
(\mathbf{n}=\mathbf{1 6})\end{array}$ & $\begin{array}{c}\text { HT Controls } \\
(\mathbf{n}=\mathbf{6})\end{array}$ & $\mathbf{p}$ \\
\hline Global Myocardium & $-1.79+/-9.13$ & $17.36+/-9.19$ & 0.0004 \\
\hline LAD & $-3.08+/-14.37$ & $18.97+/-2.39$ & 0.0016 \\
\hline LCX & $1.49+/-13.66$ & $14.29+/-18.74$ & 0.097 \\
\hline RCA & $-5.03+/-8.47$ & $17.21+/-12.21$ & 0.0001 \\
\hline
\end{tabular}

\section{Conclusions}

Chronic renal failure patients have global reductions in myocardial oxygenation even controlling for the degree of LVH. BOLD CMR is a promising tool to detect myocardial ischemia in the renal failure population, and may form a novel risk predictor of cardiovascular prognosis.

\section{Funding}

None.

\section{Authors' details}

${ }^{1}$ Cardiology, Flinders University, Flinders Medical Centre, Bedford Park, South Australia, Australia. ${ }^{2}$ Renal Medicine, Flinders Medical Centre, Bedford Park, South Australia, Australia. ${ }^{3}$ Cardiovascular Magnetic Resonance Research, Flinders Medical Centre, Bedford Park, South Australia, Australia.

Published: 16 January 2014

- Convenient online submission

- Thorough peer review

- No space constraints or color figure charges

- Immediate publication on acceptance

- Inclusion in PubMed, CAS, Scopus and Google Scholar

- Research which is freely available for redistribution 